\title{
Introduction of More Editorial Board Members and Top Journal of the American Board of Family Medicine Reviewers
}

In an ongoing effort to introduce our readers to the eminent members of the editorial board that advises and serves the fournal of the American Board of Family Medicine, in this issue we highlight Drs. James M. Gill, Eric M. Wall, and Therese Zink.

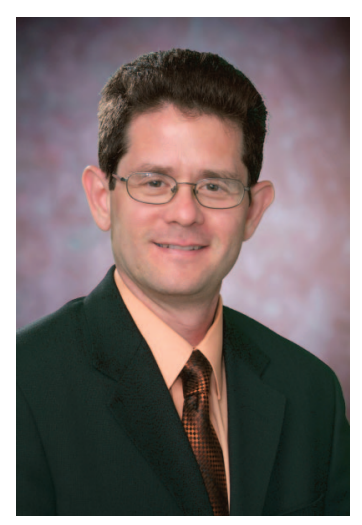

James M. Gill, MD, MPH

Dr. Gill received his medical degree from the University of Medicine and Dentistry of New Jersey and his Master's of Public Health from Johns Hopkins School of Hygiene and Public Health. President of Delaware Valley Outcomes Research, Dr. Gill is also associate professor of Family and Community Medicine and senior scientist in the Department of Health Policy at Thomas Jefferson University School of Medicine. At the University of Delaware School of Urban Affairs and Public Policy, Dr. Gill is senior policy associate and an adjunct professor. In addition, Dr. Gill is a research consultant in the Department of Family Medicine at the University of Medicine and Dentistry of New Jersey-Robert Wood Johnson Medical School, in Camden, New Jersey.

Dr. Gill conducts and publishes research in health policy, health care utilization, and quality of

Conflict of interest: The authors are editors of the $7 A B F M$. care. He has received research grants on both federal and state levels, has published widely in national medical journals, and has presented at national and international scientific meetings. Research findings are used to help guide health policy and health care delivery at a state and regional level.

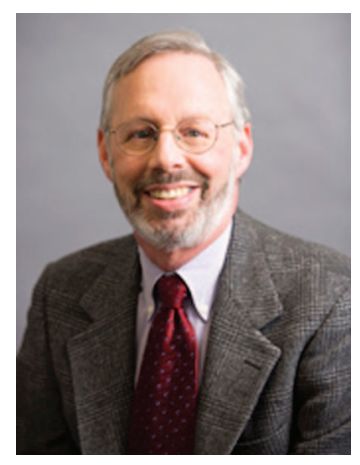

Eric M. Wall, MD, MPH

Eric M. Wall, MD, MPH, is the senior medical director of Qualis Health, a health care quality improvement and care management organization headquartered in Seattle, Washington. Dr. Wall is a board-certified family physician with more than 25 years of professional clinical experience. $\mathrm{He}$ earned his medical degree at the Catholic University of Louvain in Belgium and completed his residency at the University of Miami-Jackson Memorial Hospital in Florida. He holds a Master's in Public Health from the University of Washington. Dr. Wall served as the chair of the American Academy of Family Physicians' Commission on Science from 2005 to 2007. He currently serves on the American Medical Association's Performance Measures and Evaluation Subcommittee and was recently appointed to the Stakeholder Group for the Effective Health Care Program of the Agency for Health Care Policy and Research. 


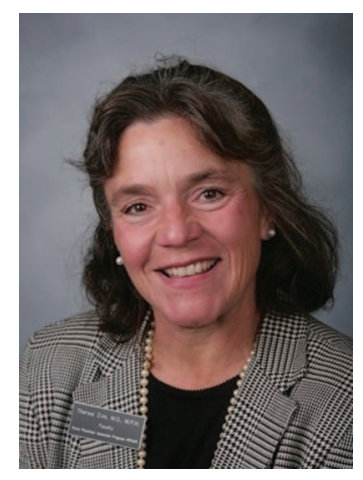

Therese Zink MD, MPH

Therese Zink, MD, MPH, is a professor in the Department of Family Medicine and Community Health at the University of Minnesota. She is currently the Associate Director of Research and Evaluation in the Rural Physician Associate Program, which places third-year medical students in small Minnesota communities for 9 months. She sees patients at the Fairview Zumbrota clinic and precepts at the St John's Family Medicine Residency program. Her current research interests include rural physician supply and violence. Using mixed methods (qualitative and quantitative) she has examined the care of domestic violence survivors/ victims in primary care. Dr. Zink and her research team have interviewed more than 100 domestic violence survivors about their experiences as victims when seeking assistance from health care. Her research has been published in family, pediatric, and internal medicine and social science journals. Dr. Zink has presented her work at international and national research meetings. Currently she is a coinvestigator on a \$1.5 million National Institutes of Health grant that examines health disparities in the sexual assault examination. She was awarded the Researcher of the Year Award in 2008 by the Minnesota Academy of Family Physicians.

\section{TopJournal of the American Board of Family Medicine Reviewers}

Each peer review of submitted manuscripts that the Fournal of the American Board of Family Medicine receives is evaluated and score by the editors, and the following peer reviewers are in the top $10 \%$ (based on evaluation scores plus quantity of reviews) of all reviewers from July 2008 through June 2009. We want to acknowledge these reviewers for the peer reviewing service that they have provided to the fournal. Their critiques and insights are a crucial component of this journal's quality and its ability to serve as a forum for the advancement of knowledge in the field of family medicine.

William A. Alto

Alfred O. Berg

Larry Culpepper

L. Miriam Dickinson

Steven A. Dosh

Tanya Dougherty

William G. Elder

John W. Ely

Kenneth S. Fink

Colleen T. Fogarty

James M. Gill

Dwenda K. Gjerdingen

Adam O. Goldstein

Rise B. Goldstein

Beverly B. Green

Larry A. Green

Tomas L. Griebling

David L. Hahn

Masahito Jimbo

Patricia M. Lenahan

Helen E. McIlvain

James W. Mold

Zsolt J. Nagykaldi

Wilson D. Pace

Donald Pathman

Howard K. Rabinowitz

Dean A. Seehusen

Jun Shu

Peter C. Smith

Douglas Smucker

Peter G. Teichman

Matthew E. Ulven

Anthony J. Viera

Barbara P. Yawn

Adam J. Zolotor

\section{Special Geographic Information Systems Issue}

Look for our theme issue scheduled for January 2010 that will feature articles with a geographic information systems methodology and will discuss the impact that geographic information systems is having on family medicine.

Phillip Lupo, MLIS Anne Victoria Neale, PhD, MPH Marjorie A. Bowman, MD, MPA 